Article

\title{
Novel Capsular Polysaccharide from Lobochlamys segnis
}

\author{
Gino Schiano di Visconte ${ }^{1,2, *}$, Michael J. Allen ${ }^{2,3}$ (D) and Andrew Spicer ${ }^{1}$ \\ 1 Algenuity Limited, Eden Laboratory, Broadmead Road, Stewartby MK43 9ND, UK; aps@algenuity.com \\ 2 College of Life and Environmental Sciences, Streatham Campus, University of Exeter, Exeter EX4 4QD, UK; \\ mija@pml.ac.uk \\ 3 Plymouth Marine Laboratory (PML), Prospect Place, The Hoe, Plymouth PL1 3DH, UK \\ * Correspondence: gs@algenuity.com
}

Citation: Schiano di Visconte, G.; Allen, M.J.; Spicer, A. Novel Capsular Polysaccharide from Lobochlamys segnis. Polysaccharides 2021, 2, 121-137. https://doi.org/10.3390/ polysaccharides 2010009

Academic Editor: Cédric Delattre

Received: 12 January 2021

Accepted: 19 February 2021

Published: 3 March 2021

Publisher's Note: MDPI stays neutral with regard to jurisdictional claims in published maps and institutional affiliations.

Copyright: (c) 2021 by the authors. Licensee MDPI, Basel, Switzerland. This article is an open access article distributed under the terms and conditions of the Creative Commons Attribution (CC BY) license (https:// creativecommons.org/licenses/by/ $4.0 /)$.

\begin{abstract}
In recent years there has been a significant effort from food, nutraceutical, cosmeceutical, pharmaceutical, and biomedical industries to discover and develop new natural ingredients. Microalgae have been recognised as potential sources of high value chemicals, with most attention focused upon antioxidants, pigments, and specialty oils. An under-exploited group of biochemicals produced by microalgae are extracellular polymeric substances (EPS). Lobochlamys segnis (formerly called Chlamydomonas segnis) was previously reported to produce a large amount of capsular polysaccharide (CPS) closely related to hyaluronan (HA) under stress conditions. In this work, the purified CPS was characterised and shown to have an average molecular mass $(\mathrm{Mn})$ of about $3.7 \mathrm{MDa}$, and displayed a highly branched random coil structure unlike the simple repeating linear HA polysaccharide. Chemical analysis showed the presence of galactose, glucuronic acid, and glucose sugars confirming that the product has a different composition to that of HA. Mixotrophic growth and stress conditions were identified and improved upon with a $\mathrm{pH}$ control system using acetic acid solution to induce efficient production of CPS. Extraction and purification conditions were also identified exploiting the high Mn of the product. The CPS showed thickening properties and both significant antioxidant capacity and reducing power, which could have commercial applications. This is the first report on the characterization of this novel polysaccharide with non-Newtonian properties similar to HA.
\end{abstract}

Keywords: microalgae; biotechnology; EPS; hyaluronan

\section{Introduction}

Polysaccharides (PS) are long chains of linear or branched sugar monomers linked through glycosidic bonds. Depending on the composition, size, and structure, PS can have a range of physico-chemical properties including antioxidant, stabilizing, suspending, thickening, flocculating, encapsulating, emulsifying, and water retention [1]. Some PS also possess biological activities such as antiviral, anticoagulant, immunomodulating, and antitumoral activities [2]. Due to these characteristics, PS can be used in a variety of different commercial applications, including biomedical devices, pharmaceuticals, cosmetics, adhesives, detergents, food additives, textiles, brewing, and wastewater treatments [1].

Hyaluronan (HA) is a linear, polydisperse, high molecular weight (MW) glycosaminoglycan (GAG), composed of alternating repeats of $\beta-1,4$-D-glucuronic acid and $\beta-1,3-\mathrm{N}$ acetyl-D-glucosamine units [3]. In addition to being highly biocompatible and biodegradable, the basic physicochemical properties of HA that are of relevance to biomedical applications are related to viscosity, elasticity, lubrication, and its high capacity for water retention [4].

Lobochlamys segnis (L.s.), previously known as Chlamydomonas segnis [5], is a freshwater, green microalgae that was considered in the past for its fatty acid profile rich in polyunsaturated fatty acids (PUFAs) [6]. Under general stress conditions, such as high light intensities or nitrogen starvation, the cultivation of this species becomes difficult due to the substantial production of extracellular polysaccharides (EPS; thought to be HA or 
HA-like) that increase the viscosity of the culture [7]. This was considered to be a limitation during the production of PUFAs [8].

In this study, rather than viewing the EPS as a problematic by-product, we sought to evaluate L.s. as a platform for its optimised production and assessed its potential for exploitation. In the first instance, the effects of culture conditions and media composition were tested in order to increase the biomass concentration in stationary phase. After that, a panel of stress-inducing conditions were applied and the appearance of the culture was evaluated, with the aim of reaching high culture viscosity due to EPS production. Once the EPS production was increased, extraction and purification conditions were determined. Purified EPS was characterised for its sugar composition, molecular weight (MW), and glycosidic linkages. Rheological properties and antioxidant activity were also determined and directly compared with those for HA. Interest in alternatives to traditional HA is fuelled by current challenges associated with its production as well as achieving monodisperse high MW product of high purity. In a market expected to reach USD 16.6 billion by 2027 [9], these two aspects make the exploration of alternative HA supply chain sources, or new methods for its production not only scholastically intriguing but also relevant based on the industrial and economic potential.

Based on our results, the EPS produced by Lobochlamys segnis under stress conditions is not HA, being, rather, a branched complex high MW polysaccharide. We discuss possible applications for the purified EPS as a biomedical functional alternative to HA as well as its potential as an antioxidant, preservative, water retention agent, or thickening agent in food and/or cosmetics.

\section{Materials and Methods}

\subsection{Chemicals}

Culture media components were purchased from VWR, UK. Proteinase K was purchased from New England Biolabs, UK. All other chemicals and enzymes used were purchased from Merck, UK.

\subsection{Microalgae Strain Selection and Growth/Stress Conditions Determination}

Three strains of L.s. were initially obtained from the culture collection of algae at Goettingen University (SAG) [10]: SAG 52.72 isolated in Czech Republic, SAG 11-13 isolated in United Kingdom, and SAG 1.79 isolated in Canada. All three strains were kept on Trisacetate-phosphate (TAP) medium [11] 1.5\% agar plates and re-streaked every month.

Two media, prepared as per reference, were tested, TAP medium [11] and High salt medium (HSM) [12]. Three nitrogen sources were tested for TAP medium, all at the same molar concentration as per reference. Cultures were grown in Algem ${ }^{\circledR}$ HT24 photobioreactor [13] in $25 \mathrm{~mL}$ volume inside a $50 \mathrm{~mL}$ clear flask or Algem PRO photobioreactor [13] in $400 \mathrm{~mL}$ volume in a $1 \mathrm{~L}$ Pyrex erlenmeyer flask, at $28^{\circ} \mathrm{C}$ with white LED light intensity set at 200 micromoles $/ \mathrm{m}^{2} / \mathrm{s}\left(\mu \mathrm{M} / \mathrm{m}^{2} / \mathrm{s}\right.$ microEinsteins $\left.[\mu \mathrm{E}]\right)$ photosynthetically active radiation (PAR) measuring the $\mathrm{OD}$ at $740 \mathrm{~nm}$ every $10 \mathrm{~min}$. As a stress inducer, $4000 \mu \mathrm{E}$ light intensity was applied with red:blue:white ratio of 1:1:2 in the Algem photobioreactor. The mixing was set to $120 \mathrm{rpm}$ with a gas aeration rate of $25 \mathrm{~mL} / \mathrm{min}$ of $30 \% \mathrm{CO}_{2}$ in order to control the $\mathrm{pH}$ of the culture at $\mathrm{pH} 7$ via computer-controlled solenoid valve. For the acetic acid feeding, a 1 molar solution was prepared in purified water and used under the control of a modified version of the Algem software with a peristaltic pump [13] in order to keep the $\mathrm{pH}$ of the culture at 7 and with a continuous aeration rate of $50 \mathrm{~mL} / \mathrm{min}$ of air.

\subsection{Extraction of Extracellular Polymeric Substances}

All samples, except when specified, were extracted at $37^{\circ} \mathrm{C}$ mixing with a magnetic stir bar for $24 \mathrm{~h}$. All enzymatic and non-enzymatic extraction processes were tested independently under the following conditions: 
- $\quad$ Lysozyme lyophilized powder from chicken egg white was resuspended at $10 \mathrm{mg} / \mathrm{mL}$ in $10 \mathrm{mM}$ Tris- $\mathrm{HCl} \mathrm{pH} 8$ immediately before use and was used at $1 \mathrm{mg} / \mathrm{mL}$ in solution with EPS.

- $\quad$ Lyticase powder from Arthrobacter luteus was resuspended at $10 \mathrm{mg} / \mathrm{mL}$ in $67 \mathrm{mM}$ Potassium Phosphate Buffer $\mathrm{pH} 7.5$ immediately before use and was used at $1 \mathrm{mg} / \mathrm{mL}$ in the same buffer solution with EPS at $25^{\circ} \mathrm{C}$.

- Sulfatase powder from Helix pomatia was resuspended at 10 units $/ \mathrm{mL}$ in $200 \mathrm{mM}$ Sodium Acetate Buffer, pH 5.0 immediately before use and was used at 1 unit $/ \mathrm{mL}$ in buffer solution with EPS.

- Chitinase powder from Streptomyces griseus was resuspended at $1 \mathrm{mg} / \mathrm{mL}$ in purified water immediately before use and was used at $0.5 \mathrm{mg} / \mathrm{mL}$ in solution with EPS.

- Proteinase K was used at 3 units / $\mathrm{mL}$ in $15 \mathrm{mM}$ Tris- $\mathrm{HCl} \mathrm{pH}$ 7.6, $1.5 \mathrm{mM} \mathrm{CaCl} 0.6 \%$ SDS solution with EPS.

- Hyaluronidase from bovine testes was resuspended at $1 \mathrm{mg} / \mathrm{mL}$ in $20 \mathrm{mM}$ phosphate buffer, $\mathrm{pH} 7$, with $77 \mathrm{mM}$ sodium chloride and $0.01 \%$ BSA immediately before use and was used at $0.5 \mathrm{mg} / \mathrm{mL}$ in solution with EPS.

- Sodium dodecyl sulphate (SDS) at $1 \%$ or $6 \%$ final concentration in water.

- Applying heat at $100^{\circ} \mathrm{C}$ for $6 \mathrm{~h}$ or $24 \mathrm{~h}$ or $121^{\circ} \mathrm{C}$ for $15 \mathrm{~min}$ every $100 \mathrm{~mL}$ in autoclave.

- Urea at $1 \mathrm{M}$ and $10 \mathrm{M}$ final concentrations.

- Potassium hydroxide (KOH) $5 \%$ final concentration.

- Sodium chloride $(\mathrm{NaCl}) 2 \mathrm{M}$ final concentration.

After extraction, samples were centrifuged once at 21,000 relative centrifugal force (rcf) for $5 \mathrm{~min}$. The un-extracted part of the sample (cells and cell debris) formed a pellet and the extracted EPS was in solution in the transparent supernatant.

\subsection{Agarose Gel Electrophoresis}

A TBE buffer gel was prepared with $0.5 \%$ agarose and run for $1 \mathrm{~h}$ at 160 volts. Samples were prepared adding 1 volume of loading dye, composed of $2 \mathrm{M}$ sucrose in TBE $(1 \times)$ with $1 / 20$ of final volume bromophenol blue, to 5 volume of sample. The gel was equilibrated in a Petri dish at room temperature, mixing for $1 \mathrm{~h}$ with $40 \%$ ethanol in purified water. The gel was stained with Stains-All (Merck, UK) working solution at room temperature for $24 \mathrm{~h}$; $0.1 \%$ Stains-All stock solution was prepared in formamide $(10 \mathrm{mg}$ in $10 \mathrm{~mL})$, for working solution, $2.5 \mathrm{~mL}$ of stock solution, $2.5 \mathrm{~mL}$ formamide, $12.5 \mathrm{~mL}$ isopropanol, $0.25 \mathrm{~mL}$ of $3 \mathrm{M}$ Tris- $\mathrm{HCl} \mathrm{pH} \mathrm{8.8,} \mathrm{and} 32.25 \mathrm{~mL}$ of purified water were mixed. The gel was de-stained with light for $10 \mathrm{~min}$ after rinsing with water first and then with $70 \%$ denatured ethanol.

\subsection{Filtration}

An extracted sample was clarified with a glass microfiber $0.45 \mu \mathrm{m}$ filter. After clarification, the extracted samples were filtered with a Minimate $500 \mathrm{kDa}$ tangential flow filtration (TFF) capsule (Pall Corporation) following manufacturer's recommendations, until reaching a reduction of volume of $90 \%$. Purified water was used to reconstitute the concentrate to the original volume, twice, in order to remove low MW contaminants and to desalt. The filtrate was collected for further processing with a $30 \mathrm{kDa}$ molecular weight cut-off capsule as described for the previous filtration process.

\subsection{High MW EPS Purification with Sephacryl Size Exclusion Chromatography}

A glass column with $46 \mathrm{~cm}$ length and $1 \mathrm{~cm}$ internal diameter was used with Sephacryl ${ }^{\circledR}$ 500-HR (Merck, UK) and $0.15 \mathrm{M} \mathrm{NaCl}, 0.05 \mathrm{M}$ phosphate $\mathrm{pH} 7$ running buffer with a flow rate of $2 \mathrm{~mL}$ per minute; $0.3 \mathrm{M} \mathrm{NaCl}$ final concentration was added to each sample before loading on the column. One millilitre fractions were collected and precipitated by addition of 3 volumes of acetone and centrifugation at $4600 \mathrm{rcf}$. After the supernatant was removed, the pellet was air-dried and resuspended in TBE at $4{ }^{\circ} \mathrm{C}$ overnight followed by gel electrophoresis analysis as described above. Once the fractions with the higher 
molecular weight product were selected, the samples were pooled and desalted with TFF as previously described.

\subsection{Freeze Dry}

Purified high MW EPS was frozen at $-40{ }^{\circ} \mathrm{C}$ and dried in a lab scale vacuum freeze dryer (Harvest Right, UT, US) at $-5{ }^{\circ} \mathrm{C}$ heating shelf temperature, 200 mTorr cavity pressure, and $-40{ }^{\circ} \mathrm{C}$ cold trap temperature for $24 \mathrm{~h}$ in a glass Petri dish.

\subsection{Polysaccharide MW Analysis}

One $\mathrm{mL}$ of $0.1 \mathrm{M} \mathrm{NaNO}_{3}$ was added to the freeze-dried polysaccharide sample; it was heated up to $100{ }^{\circ} \mathrm{C}$ for complete dissolution and centrifuged for $10 \mathrm{~min}$ at 14,000 rcf. The supernatant was collected for analysis, with $0.1 \mathrm{~mL}$ injected per sample; this was performed with GPC-RI-MALS platform with the column temperature set to $60{ }^{\circ} \mathrm{C}, 0.1 \mathrm{M}$ $\mathrm{NaNO}_{3}$ mobile phase with a flow of $0.4 \mathrm{~mL} /$ minutes. From the comparison of the retention time of the EPS sample with the same data from a set of standards of known MW solution, it was possible to determine the MW distribution of the sample.

\subsection{Glycosyl Composition Analysis}

Analysis was undertaken by combined gas chromatography/mass spectrometry (GC/MS) of the per-O-trimethylsilyl (TMS) derivatives of the monosaccharide methyl glycosides produced from the sample by acidic methanolysis [14,15]. Approximately $0.25 \mathrm{mg}$ of the sample was heated with methanolic $\mathrm{HCl}$ in a sealed screw-top glass test tube for $17 \mathrm{~h}$ at $80^{\circ} \mathrm{C}$. After cooling and removal of the solvent under a stream of nitrogen, the sample was treated with a mixture of methanol, pyridine, and acetic anhydride for $30 \mathrm{~min}$. The solvents were evaporated and the sample derivatized with Thermo Tri-Sil HTP (HDMS:TMCS:Pyridine) reagent at $80^{\circ} \mathrm{C}$ for $30 \mathrm{~min}$ with added inositol as internal standard. GC/MS analysis of the TMS methyl glycosides was performed on an Agilent 7890A GC interfaced to a 5975C MSD, using a Supelco Equity-1 fused silica capillary column $(30 \mathrm{~m} \times 0.25 \mathrm{~mm}$ ID).

\subsection{Glycosyl Linkage Analysis from Creative Proteomics}

Approximately $1 \mathrm{mg}$ of sample was treated with $0.5 \mathrm{M}$ methanolic $\mathrm{HCl}$ for 20 min at $80{ }^{\circ} \mathrm{C}$. It was then dried, and reduction of the newly formed carboxylic esters was accomplished using $0.4 \mathrm{~mL}$ of a $10 \mathrm{mg} / \mathrm{mL}$ solution NaBD4 in water overnight. The sample was neutralised with acetic acid, dried thoroughly, and later suspended in $0.2 \mathrm{~mL}$ of dimethyl sulfoxide. Per-methylation of the sample was affected by two rounds of treatment, first with sodium hydroxide for $15 \mathrm{~min}$ and then with methyl iodide for $45 \mathrm{~min}$. The sample was hydrolysed using $0.1 \mathrm{M}$ TFA for $30 \mathrm{~min}$ in a sealed tube at $100{ }^{\circ} \mathrm{C}$, reduced with NaBD4, hydrolysed again using $2 \mathrm{M}$ TFA for $2 \mathrm{~h}$ in a sealed tube at $100{ }^{\circ} \mathrm{C}$, and acetylated using acetic anhydride/TFA $[16,17]$. The resulting partially methylated alditol acetates (PMAAs) were analysed on an Agilent 7890A GC interfaced to a 5975C MSD (mass selective detector, electron impact ionization mode); separation was performed on a $30 \mathrm{~m}$ SP2330 bonded phase fused silica capillary column.

\subsection{Rheology Analysis}

Flow sweep measurements of viscosity were implemented using Discovery HR-3 hybrid rheometer with a hard-anodised aluminium $40 \mathrm{~mm}$ Peltier parallel plate with Solvent Trap. The gap was set to $500 \mu \mathrm{m}$ and the analysis was performed with samples at $25{ }^{\circ} \mathrm{C}$ with a shear rate changing between 0.1 to $1000 \mathrm{~s}^{-1}$ measuring 5 points per decade, with equilibrium time of $1 \mathrm{~min}$. One millilitre of the sample was loaded and the excess was wiped out. HA standard solution was made dissolving pure 5 MDa MW HA at a concentration of $8.34 \mathrm{mg} / \mathrm{mL}$ in purified water. L.s. stressed cells were resuspended in TAP medium. L.s. EPS was extracted with heat treatment, debris was filtered, and the clear solution was concentrated with $500 \mathrm{kDa}$ molecular weight cut-off membrane at about 
$14 \mathrm{mg} / \mathrm{mL}$. NaCl was added to the samples to a final concentration of $2 \mathrm{M}$ to investigate the impact on the viscosity of the solution.

\subsection{Antioxidant Capacity and Reducing Power Quantification Assays}

Heat extracted L.s. EPS samples were concentrated with $500 \mathrm{kDa}$ filter and freezedried without purification in order to resuspend them in purified water at a known concentration for measurement of total antioxidant capacity and reducing power. The total antioxidant capacity was measured based on the reduction of $\mathrm{Mo}^{6+}$ to $\mathrm{Mo}^{5+}[18]$. Aliquots of the polysaccharide solution $(0.1 \mathrm{~mL})$ at different concentrations $(0.5 \%, 0.75 \%$, $1 \%, 1.25 \%, 1.5 \%$ ) were mixed with $1 \mathrm{~mL}$ of the reagent solution ( $0.6 \mathrm{M}$ sulfuric acid, $28 \mathrm{mM}$ sodium phosphate $\left(\mathrm{NaH}_{2} \mathrm{PO}_{4}\right)$, and $4 \mathrm{mM}$ ammonium molybdate). This step was followed by incubation at $95^{\circ} \mathrm{C}$ for $90 \mathrm{~min}$. Subsequently, the absorbance was read at $695 \mathrm{~nm}$. A standard curve under the same conditions was prepared with solutions of ascorbic acid $(0.005 \%, 0.004 \%, 0.01 \%, 0.0125 \%, 0.015 \%)$ in purified water. The assays were carried out in triplicate and the results are presented as equivalence of ascorbic acid (mg EAscA/g of sample).

The reducing power was determined according to published method [19]. Two hundred microliters of EPS in purified water $(1.5 \%, 15 \mathrm{mg} / \mathrm{mL})$ were mixed with an equal volume of both $0.2 \mathrm{M}$ sodium phosphate buffer ( $\mathrm{pH}$ 6.6) and $1 \%$ potassium ferricyanide $(10 \mathrm{~g} / \mathrm{L})$. The mixture was incubated at $50^{\circ} \mathrm{C}$ for $20 \mathrm{~min}$. After cooling down the samples, 200 microliters of $10 \%$ trichloroacetic acid $(w / v)$ were added, the mixture was centrifuged at 21,000 rcf for $10 \mathrm{~min} ; 0.5 \mathrm{~mL}$ of each supernatant was moved to a new tube and, with added $0.5 \mathrm{~mL}$ purified water and $0.1 \mathrm{~mL}$ of $0.1 \%$ of ferric chloride, samples were mixed and the absorbance was measured at $700 \mathrm{~nm}$. A standard curve was prepared with solutions of ascorbic acid $(0.005 \%, 0.0035 \%, 0.002 \%, 0.0009 \%, 0.0007 \%)$ in purified water. The assays were carried out in triplicate and the results are presented as equivalence of ascorbic acid ( $\mu \mathrm{g}$ EAscA/g of sample).

\section{Results}

\subsection{Microalgae Strain Selection and Growth/Stress Conditions Determination}

Polysaccharide production in Chlamydomonas strains has previously been reported [20,21]. Lobochlamys segnis is a microalga that is closely related to Chlamydomonas [5] and has been reported to produce an HA-like capsule under stress conditions [7]. The only other report of HA being produced within the plant kingdom, and indeed, within another green microalga, occurs when Chlorella variabilis or close relatives are infected by Chlorella viruses carrying a viral HA synthase gene [22]. While PS production in the latter occurs following transfer of the HA machinery via the viral genome, the observation of inducible HA-like polysaccharide production in the former raised the possibility of a native algal-encoded HA synthase pathway and potentially a natural source and route to a novel supply chain for this valuable polysaccharide. To investigate this possibility, three different strains of L.s. were obtained from the SAG culture collection. Of these, SAG 1.79 has previously been noted in a Canadian patent to produce a HA-like substance referred to as Chlamyhyaluronic acid [7], while the two other closely related strains were ordered for comparative purposes. On receipt, the identity of each strain was confirmed by $18 \mathrm{~S}$ PCR sequencing and maintained on agar plates for several generations. Under long term cultivation conditions, the SAG 1.79 strain was confirmed to grow as mucoid colonies. In contrast, the two other strains did not exhibit the same appearance (Figure 1). This provided a quick primary screening method for strains displaying EPS production, and SAG 1.79 was selected for further investigation. Growth was tested in two different liquid media: HSM (no carbon source) and TAP (acetate as carbon source). 


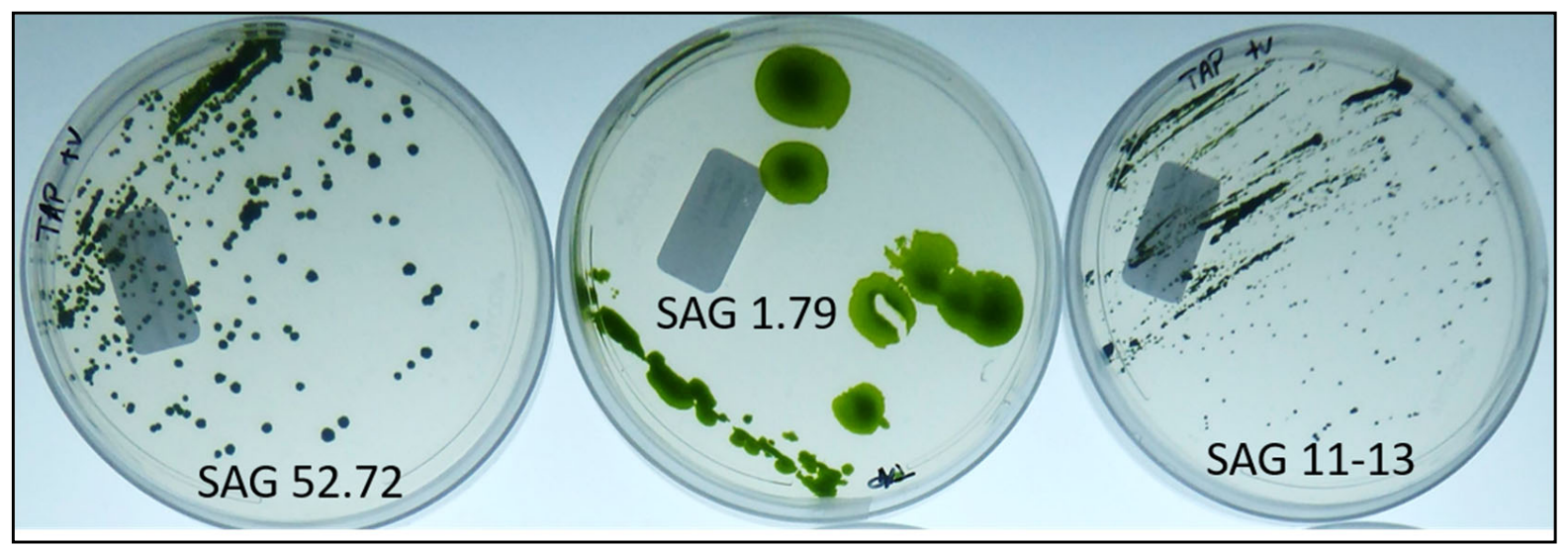

Figure 1. Solid medium plates showing the distinct mucoid appearance of the Goettingen University (SAG) 1.79 strain.

Three different nitrogen sources were tested as substrate for growth at the same molarity in TAP medium: ammonium chloride $\left(\mathrm{NH}_{4} \mathrm{Cl}\right)$, potassium nitrate $\left(\mathrm{KNO}_{3}\right)$, and urea $\left(\mathrm{CO}\left(\mathrm{NH}_{2}\right)_{2}\right)$. The growth rate as well as the cell density at stationary phase were the same for all three conditions, as shown in Figure 2.

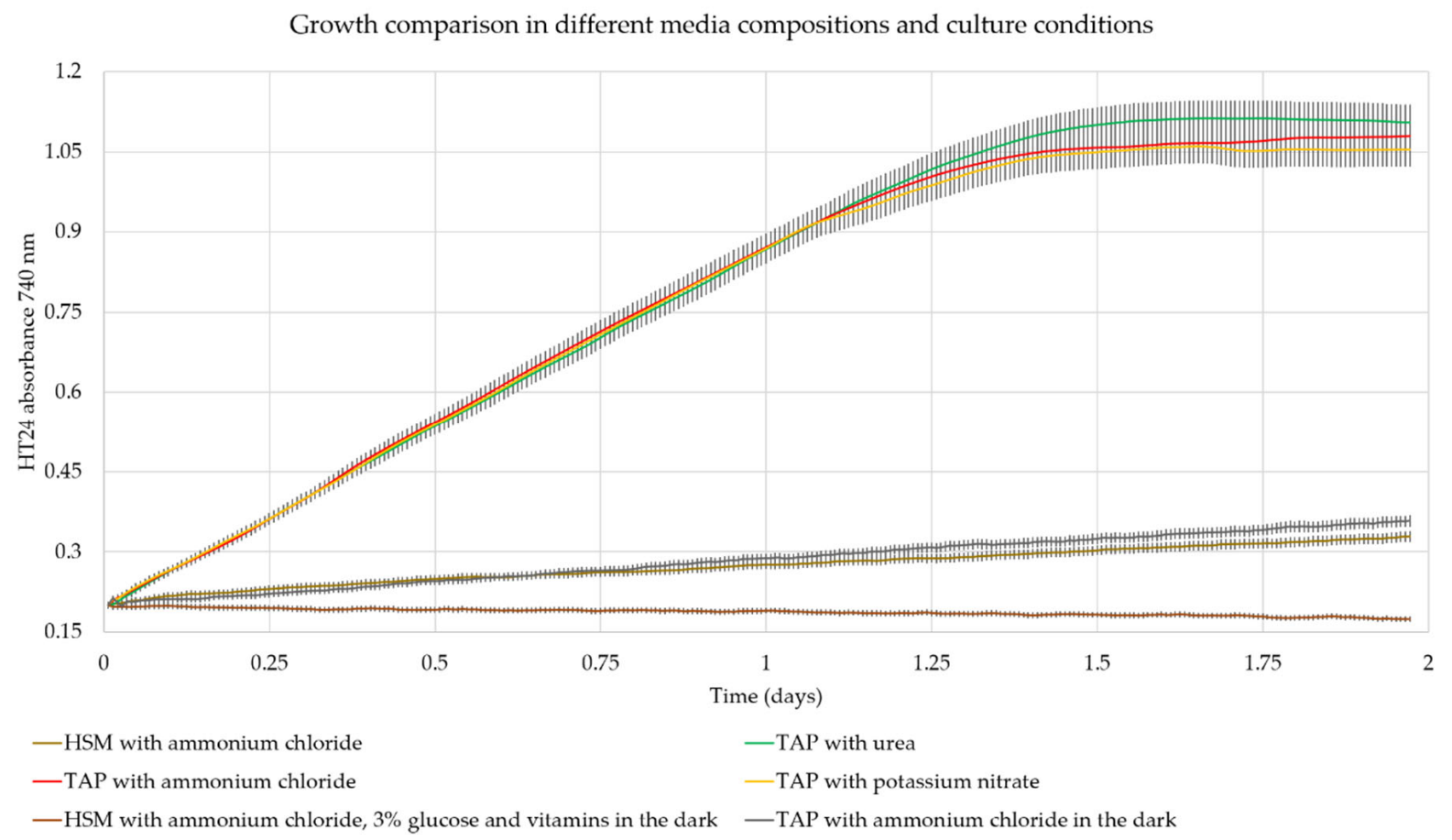

Figure 2. Growth comparison of SAG 1.79 in different media compositions and conditions. Each condition was run in triplicate, in this graph the average values are plotted with standard errors displayed for each dataset. HSM, high salt medium [12]; TAP, Tris-acetate Phosphate medium [11].

Growth in the dark was also tested utilising acetate and glucose independently as carbon sources. As shown in Figure 2, SAG 1.79 was not able to utilise glucose from the medium for growth. In contrast, the strain was able to use acetate in the dark, although showing a higher doubling time, indicating a slower growth rate. This suggests that SAG 1.79 is capable of preferential mixotrophic growth using light coupled with acetate as a carbon source. Mixotrophic growth was about three times faster than growth in the dark with acetate or the one in the light without carbon source. 
This observed behaviour suggests a synergistic effect of acetate and light, giving a higher response than a predicted additive effect when the two were used together at the same time. The possible explanation for this behaviour could be that the strain is using acetate as carbon source through the respiration pathway producing $\mathrm{CO}_{2}$ that will be used for photosynthesis using light $[23,24]$.

The doubling time $\left(\mathrm{T}_{\mathrm{d}}\right)$ for each curve, summarised in Table 1 , was calculated from data drawn from the linear portion of the growth curves (between 0.5 day and 0.75 day) using the following formula:

$$
\mathrm{T}_{\mathrm{d}} \text { (days) }=\left(0.25 \text { day } * \log _{10}(2)\right) /\left(\log _{10}(\mathrm{OD} \text { at } 0.75 \text { day })-\log _{10}(\mathrm{OD} \text { at } 0.5 \text { day })\right) \text {. }
$$

Table 1. Calculated $T_{d}$ using Algem HT24 OD readings and expressed in days for the different growth conditions.

\begin{tabular}{ccccc}
\hline $\begin{array}{c}\text { High Salt Medium } \\
\text { (HSM) with } \\
\begin{array}{c}\text { Ammonium } \\
\text { Chloride }\end{array}\end{array}$ & $\begin{array}{c}\text { Tris-Acetate } \\
\text { Phosphate Medium } \\
\text { (TAP) with } \\
\text { Ammonium } \\
\text { Chloride }\end{array}$ & $\begin{array}{c}\text { TAP with } \\
\text { Potassium } \\
\text { Nitrate }\end{array}$ & $\begin{array}{c}\text { TAP with } \\
\text { Urea }\end{array}$ & $\begin{array}{c}\text { TAP with } \\
\text { Ammonium } \\
\text { Chloride, Dark }\end{array}$ \\
\hline $3.32 \pm 0.33$ & $0.73 \pm 0.07$ & $0.75 \pm 0.08$ & $0.74 \pm 0.07$ & $2.10 \pm 0.17$ \\
\hline
\end{tabular}

Based on the information collected from these preliminary data, the nitrogen amount in the medium does not appear to be limiting the biomass density at the stationary phase; instead, the limiting factor could be the acetic acid that is the carbon source together with the $\mathrm{CO}_{2}$ from the air. A strong light stress was applied to the culture after it reached the stationary phase in order to stimulate the production of EPS. When this stress was applied, the appearance of the liquid culture did not seem to change. It is reported that a high carbon to nitrogen ratio $(\mathrm{C} / \mathrm{N})$ stimulates EPS production due to nitrogen limitation [25]. A further trial was carried out feeding the culture with acetic acid, keeping the $\mathrm{pH}$ constant at 7 using the Algem lab scale photobioreactor.

A few days after the culture reached stationary phase with acetic acid feeding, the Algem OD reading reached higher values compared to the cultures that were not fed with acetic acid (Figure 3a) showing higher viscosity behaviour (Figure 3b). Specifically, centrifugation at 21,000 rcf for $5 \mathrm{~min}$ was not sufficient to achieve a stable cell pellet. Further, light microscopy revealed cells that appeared to be evenly spaced, as if surrounded by something not visible to the eye, which caused the cells to distribute within the culture medium as if they were kept physically apart-presumably by an extracellular capsule (Figure 3c,d) forming a physical barrier.

In an effort to visualise a hypothesised capsule around the cells, a $10 \mu \mathrm{L}$ sample of each culture was diluted with 1 volume of India ink (Figure 3e,f). India ink is composed of small black particles resuspended in water that give a black background, and that would be excluded from areas occupied by a viscous physicochemical barrier such as that created by an extracellular polysaccharide capsule.

Using this technique, it was confirmed that, when stressed, cells were surrounded by a capsule that excluded the ink particles from the cell surface.

\subsection{Determination of Extraction and Purification Conditions}

In order to assess the nature of the EPS produced and reduce the viscosity of the culture, the stressed culture was exposed to a panel of enzymes and chemical treatments that degrade specific polymers. Susceptibility to the action of lysozyme, lyticase, sulphatase, chitinase, Proteinase K, hyaluronidase, 1 and 6\% SDS, heat, urea 1 and $10 \mathrm{M}, 5 \% \mathrm{KOH}$ and $2 \mathrm{M} \mathrm{NaCl}$ were assessed. After the respective treatments, samples were centrifuged at $21,000 \mathrm{rcf}$ for $5 \mathrm{~min}$. The presence of an obvious cell pellet was taken as an indication that the EPS was separated from the cells; this was possible after the extraction with heat, SDS, 
urea, $\mathrm{NaCl}$ and $\mathrm{KOH}$, with the best result achieved through applying heat alone, $100{ }^{\circ} \mathrm{C}$ for $24 \mathrm{~h}$ or autoclave at $121^{\circ} \mathrm{C}$ for $15 \mathrm{~min} / 100 \mathrm{~mL}$. Under this condition, a higher amount of the EPS was separated from the biomass compared with the other conditions. None of the enzyme digestions separated the capsular EPS from the cells nor acted to degrade the EPS. EPS extracted with heat was used for further evaluations and showed an apparent degradation pattern as seen through agarose gel electrophoresis in Figure 4.

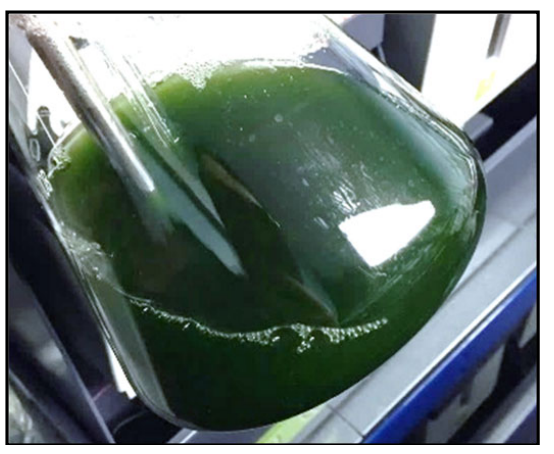

(a)

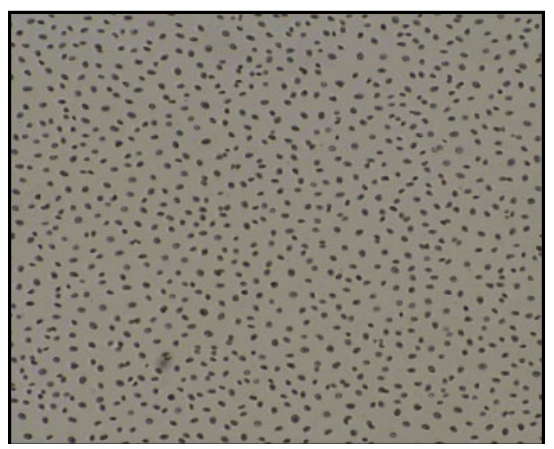

(d)

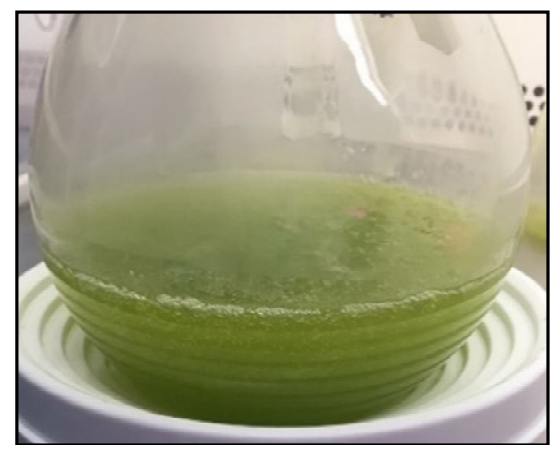

(b)

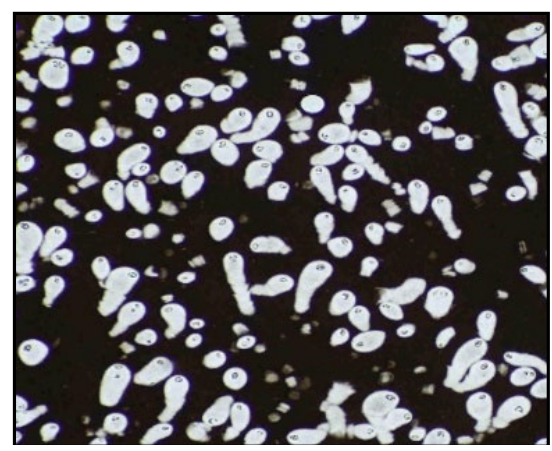

(e)

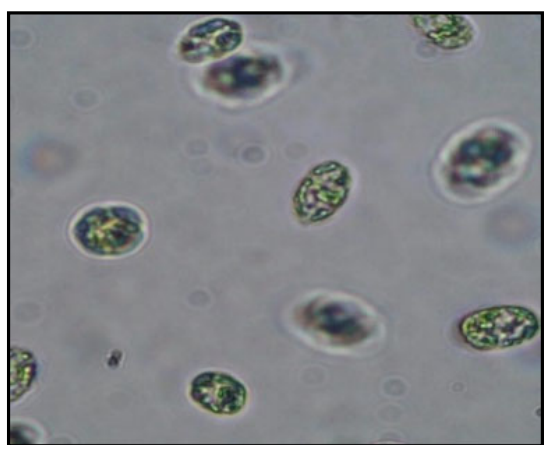

(c)

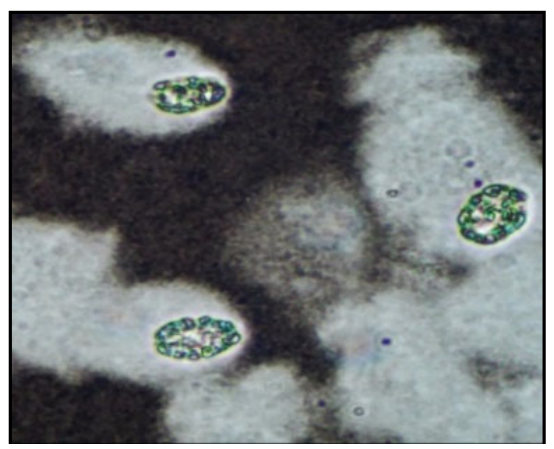

(f)

Figure 3. Visual characterisation of stressed culture. (a) Cell culture in late exponential phase; (b) stressed cell culture in late stationary phase showing suspended bubbles trapped within the viscous liquid; (c) cells in late stationary phase, $40 \times$ magnification; (d) cells in late stationary phase, $4 \times$ magnification; (e) cells in late stationary phase diluted 1:1 in Indian Ink, $4 \times$ magnification; (f) cells in late stationary phase diluted 1:1 in Indian Ink, 40× magnification.

The fact that the EPS was able to migrate within an agarose gel electrophoresis set-up using TBE buffer suggested that it possesses a net negative charge consistent with it being a polyanion. This is similar to HA or other glycosaminoglycans.

Five hundred $\mathrm{kDa}$ and $30 \mathrm{kDa}$ crossflow filtrations were tested sequentially for EPS purification from small MW contaminants. All the extracted EPS seemed to be bigger than $30 \mathrm{kDa}$. Due to the high viscosity and heterogeneity of the sample, filtration was not very efficient to separate high from low MW molecules. As shown in Figure 4, with $500 \mathrm{kDa}$ filtration, most of the high MW EPS was retained, but the low MW contaminants were still present. With the $30 \mathrm{kDa}$ filtration, everything was retained.

In order to purify high MW EPS from low MW EPS and contaminants, preparative size exclusion chromatography was tested. The different fractions were collected and assessed via gel electrophoresis (Figure 5a). All high MW fractions were pooled, washed, and resuspended in purified water (Figure 5b). The solution appeared viscous, colourless, clear, and free of any noticeable fragrance. After freeze-drying, the EPS appeared as a white aggregate that dissolved as soon as it was in contact with water (Figure $5 \mathrm{c}$ ). The yield of purified EPS was about $1 \mathrm{~g} / \mathrm{L}$ of stressed culture. 


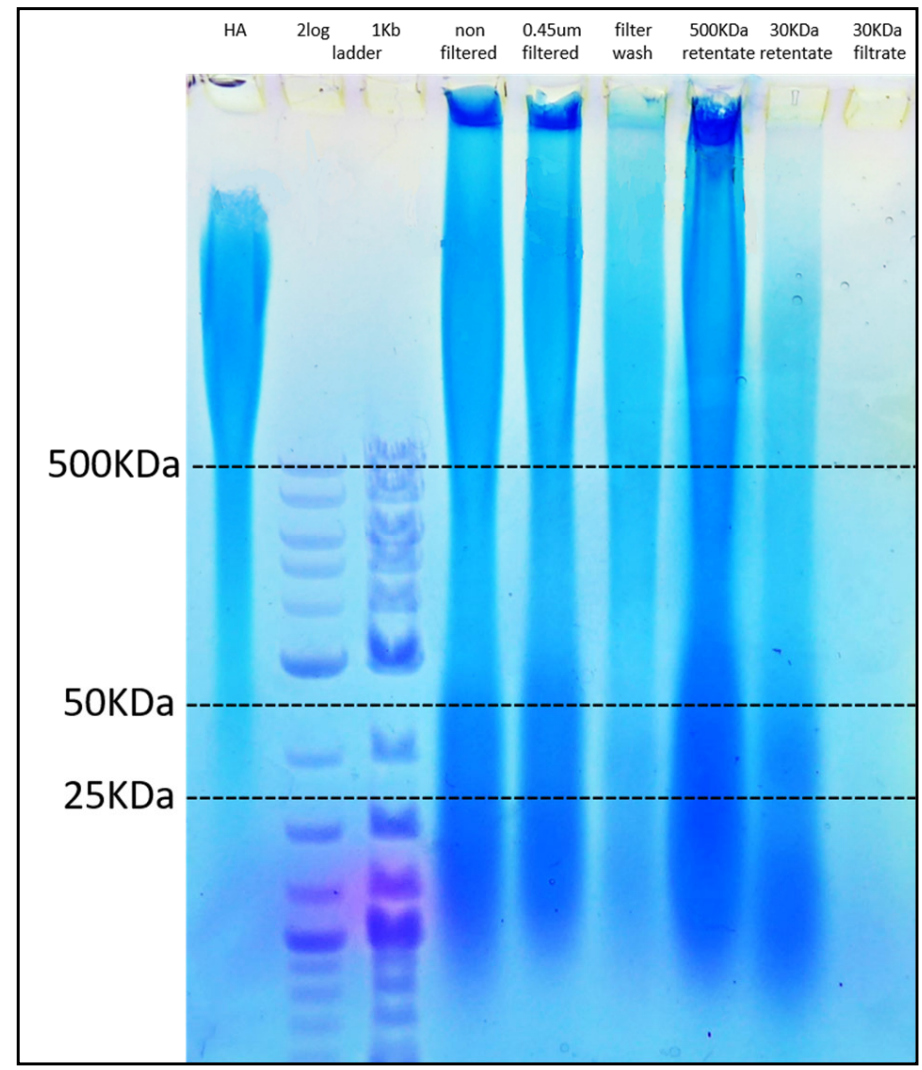

Figure 4. Agarose gel electrophoresis showing extracted and filtered samples. The first lane contained HA molecular weight standard, second and third lanes DNA ladders, fourth lane raw extracted EPS, fifth lane the $0.45 \mu \mathrm{m}$ filtered EPS, sixth lane $0.45 \mu \mathrm{m}$ filter wash, seventh lane $500 \mathrm{kDa}$ retentate, eighth lane $30 \mathrm{kDa}$ retentate, and the last lane contained the $30 \mathrm{kDa}$ filtrate; $500 \mathrm{kDa}, 50 \mathrm{kDa}$, and $25 \mathrm{kDa}$ sizes were based on the DNA ladder that was previously compared with HA size standards.

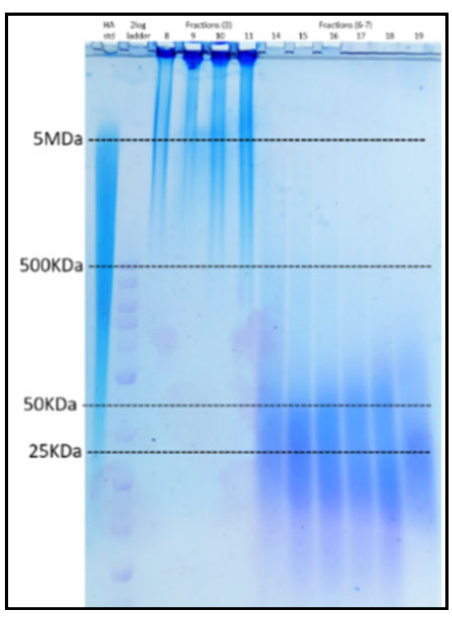

(a)

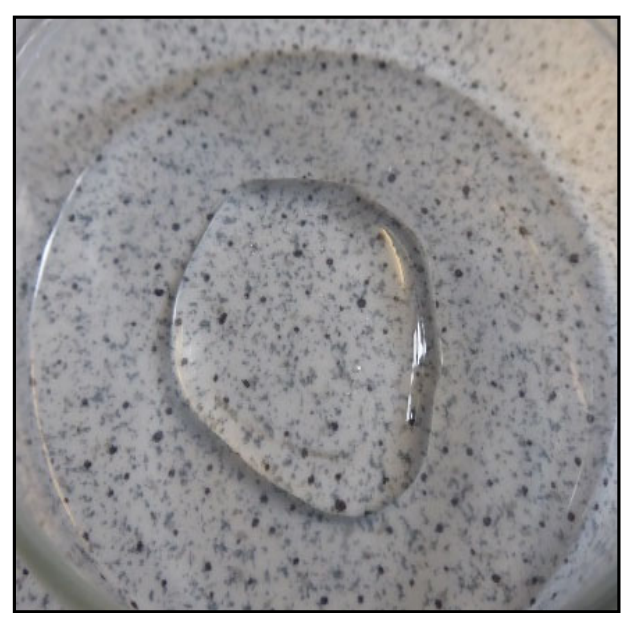

(b)

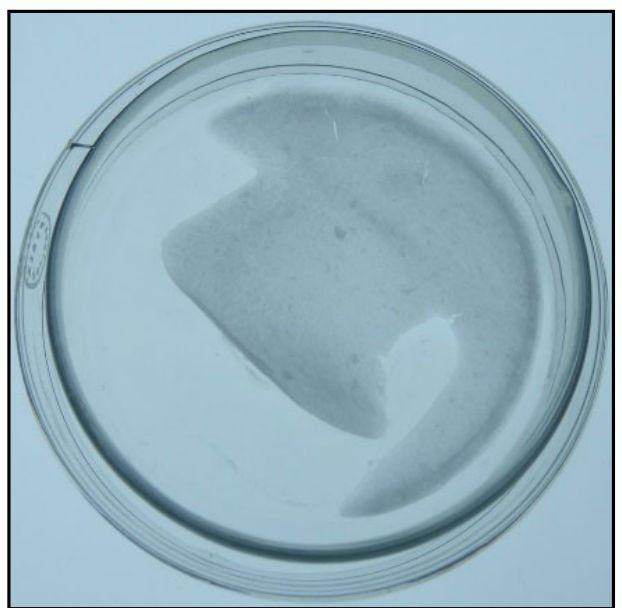

(c)

Figure 5. Size exclusion purification of high MW fractions. (a) Size exclusion fractions analysis with agarose gel electrophoresis; (b) high MW purified extracellular polymeric substances (EPS) resuspended in purified water; (c) freeze-dried high molecular weight (MW) purified EPS in a glass petri dish. 


\subsection{Molecular Size Determination and Conformation Analysis}

The number-average MW (Mn), used for kinetics studies and stoichiometric calculations, and the weight-average MW $(\mathrm{Mw})$, used to determine tensile strength, were measured and polydispersity $(\mathrm{Mw} / \mathrm{Mn})$, that is a measure of the broadness of the molar mass distribution, was calculated.

Mn was calculated as $3.673 \times 10^{6}( \pm 1.640 \%)$ Dalton (Da) or $\mathrm{g} / \mathrm{mol}$ with a polydispersity of $2.987( \pm 24.970 \%)$.

The maximum MW registered was higher than 100 megadalton (MDa) (Figure 6), but the average MW was about 3.7 MDa. This suggests that the extraction protocol may degrade or fragment the EPS as well as separating it from the cells. Improvement of the extraction protocol could increase the average MW value, altering its rheological properties and potentially enabling its application in an expanded range of cosmetics, biomedical, or food related product development opportunities.

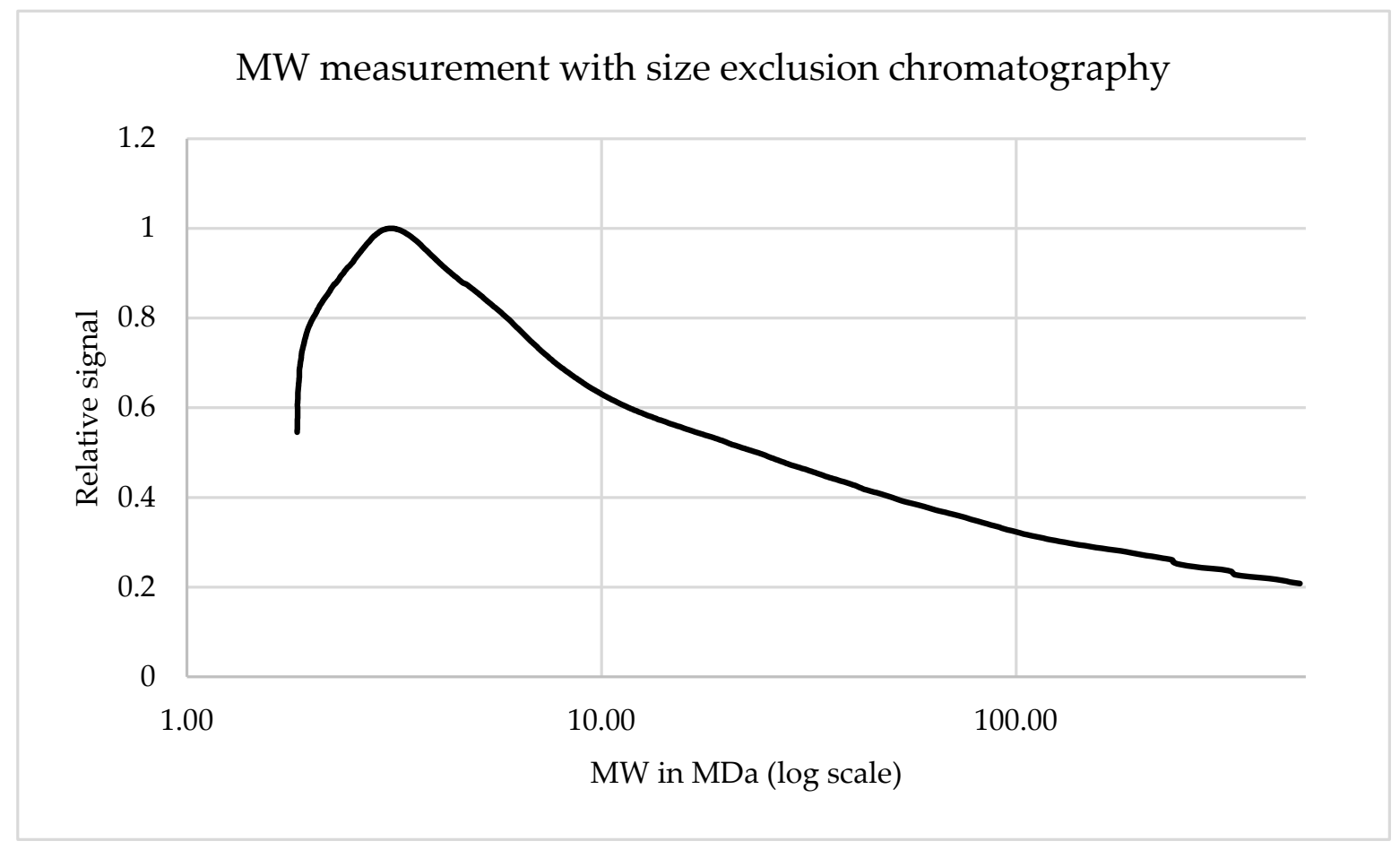

Figure 6. Chromatogram showing the MW distribution of the EPS with the relative signal showing the abundance.

The shape of the molecule can be assessed based on the relationship between the measured molar mass and root-mean-square (RMS) radius. A plot of the log of RMS radius in nanometres (nm) as a function of the log of the molar mass expressed in $\mathrm{g} / \mathrm{mol}$, called a Conformation Plot (Figure 7), shows the relationship between the two values. The slope of this graph gives a good estimate of the shape. The slope calculated for this sample is 0.55 , suggesting a flexible random coil structure. If the slope was about 0.33 , it would have suggested a branched spherical shape, and a slope of 1 would have suggested a rigid linear rod shape $[26,27]$.

\subsection{Glycosyl Composition and Glycosyl Linkage Analyses}

The freeze-dried sample was hydrolysed and analysed (Figure 8). The saccharides found in the sample were galactose, glucose and glucuronic acid along with an unidentified pyruvate containing hexose residue.

The estimated amounts and mole percentage of each detected monosaccharide in the sample is summarised in Table 2. 


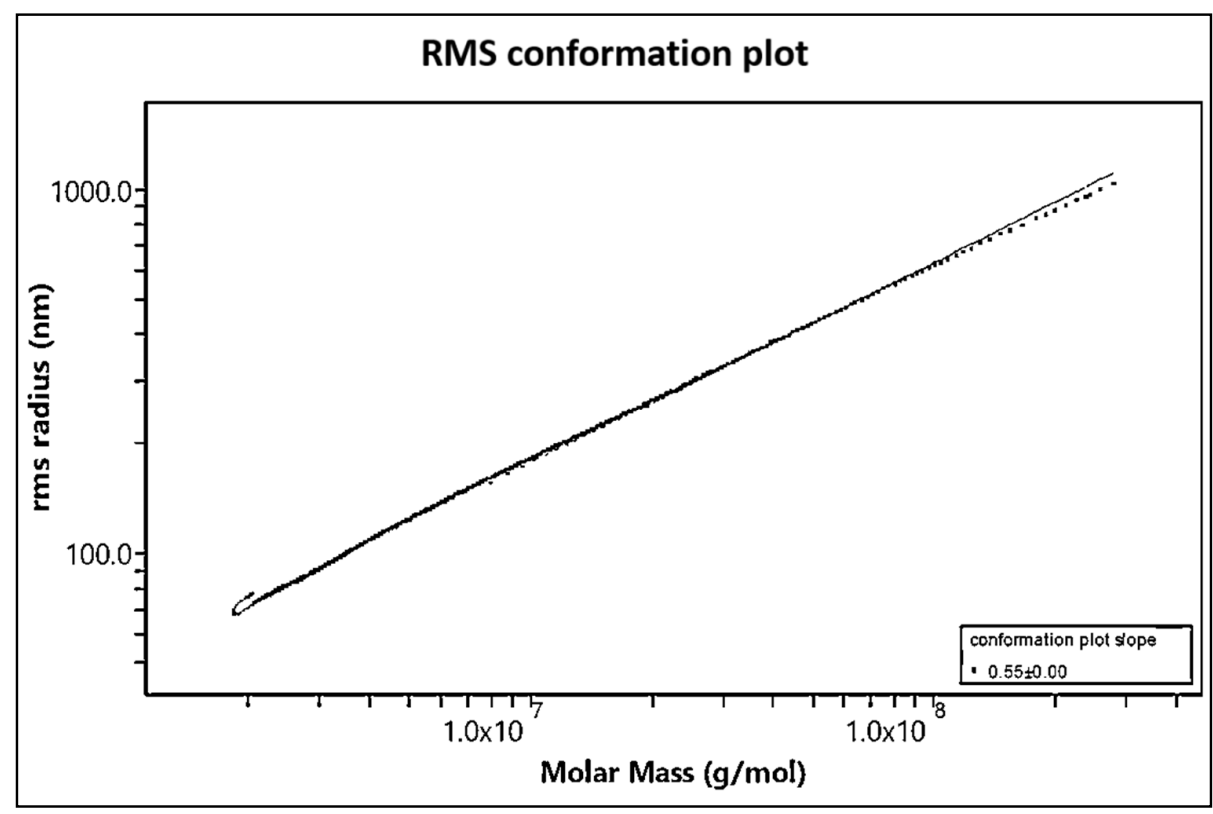

Figure 7. Root-mean-square (RMS) conformation plot of purified L.s. EPS.

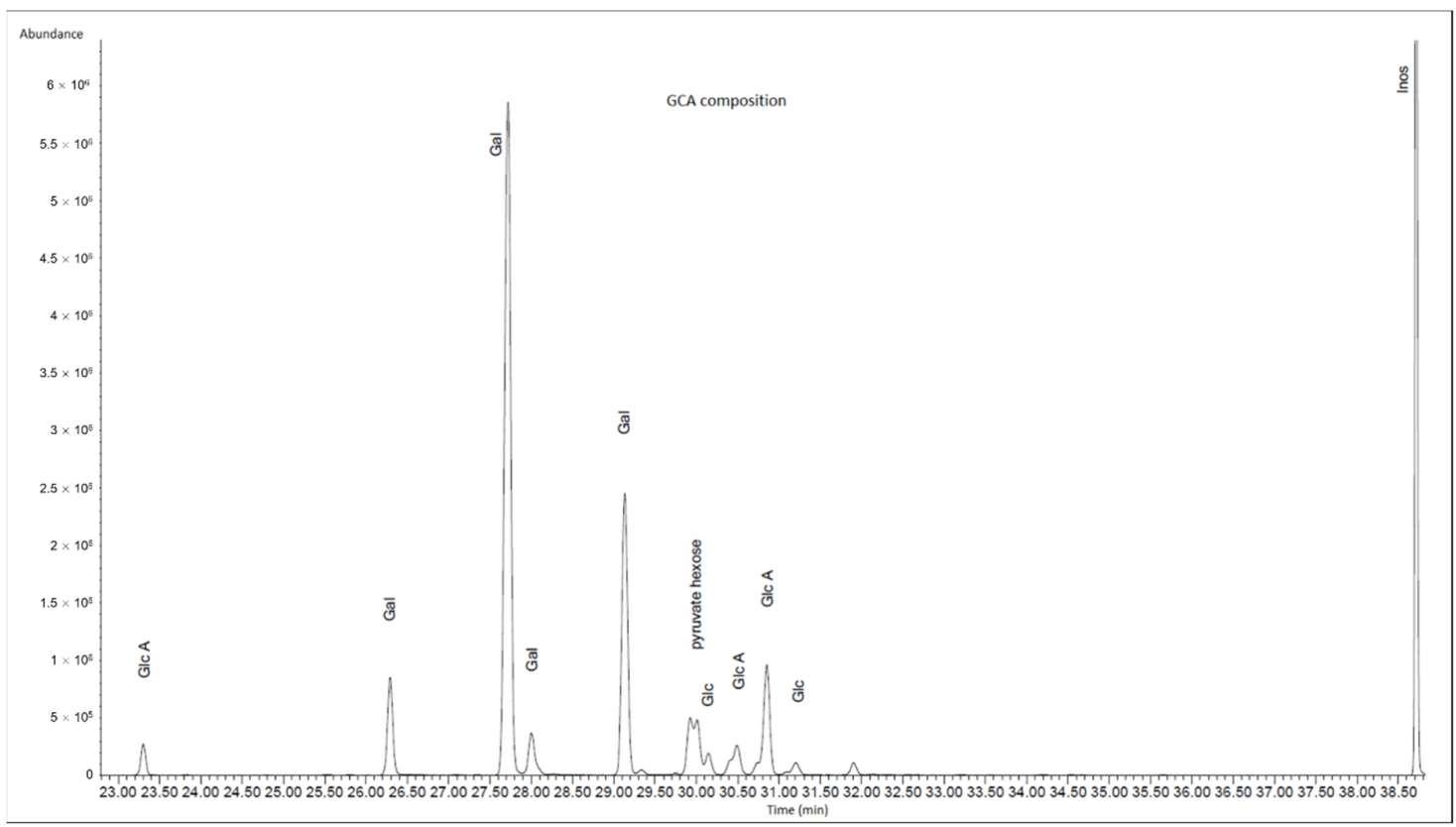

Figure 8. GC chromatogram of TMS derivatives of purified L.s. EPS sample. Relative signal strength is represented on the Y axis.

Table 2. Glycosyl composition of purified high MW EPS.

\begin{tabular}{ccc}
\hline Glycosyl Residue & Mass $(\mu \mathrm{g})$ & Mole $\%$ \\
\hline Glucuronic Acid (GlcA) & 25.8 & 18.6 \\
Galactose (Gal) & 101.4 & 78.5 \\
Glucose (Glc) & 3.7 & 2.9 \\
Total & 130.9 & 100.0 \\
\hline
\end{tabular}


Notably, $\mathrm{N}$-acetylglucosamine was not detected in the sample, demonstrating that this EPS is not HA as was previously suggested [7] and is also not a glycosaminoglycan.

Glycosyl linkage analysis was performed to identify the structure of the polysaccharide (Figure 9). The results, summarised in Table 3 , are consistent with the previously reported composition data (Table 2). The presence of the 3,4,6 linked galactopyranosyl residue and the abundance of terminal sugars suggests that the structure of the polysaccharide is complex-branched. It is possible that some of the linkages were disrupted by the strong and non-specific extraction process. There is also no clear evidence of a regular repeat pattern of the glycosyl linkages.

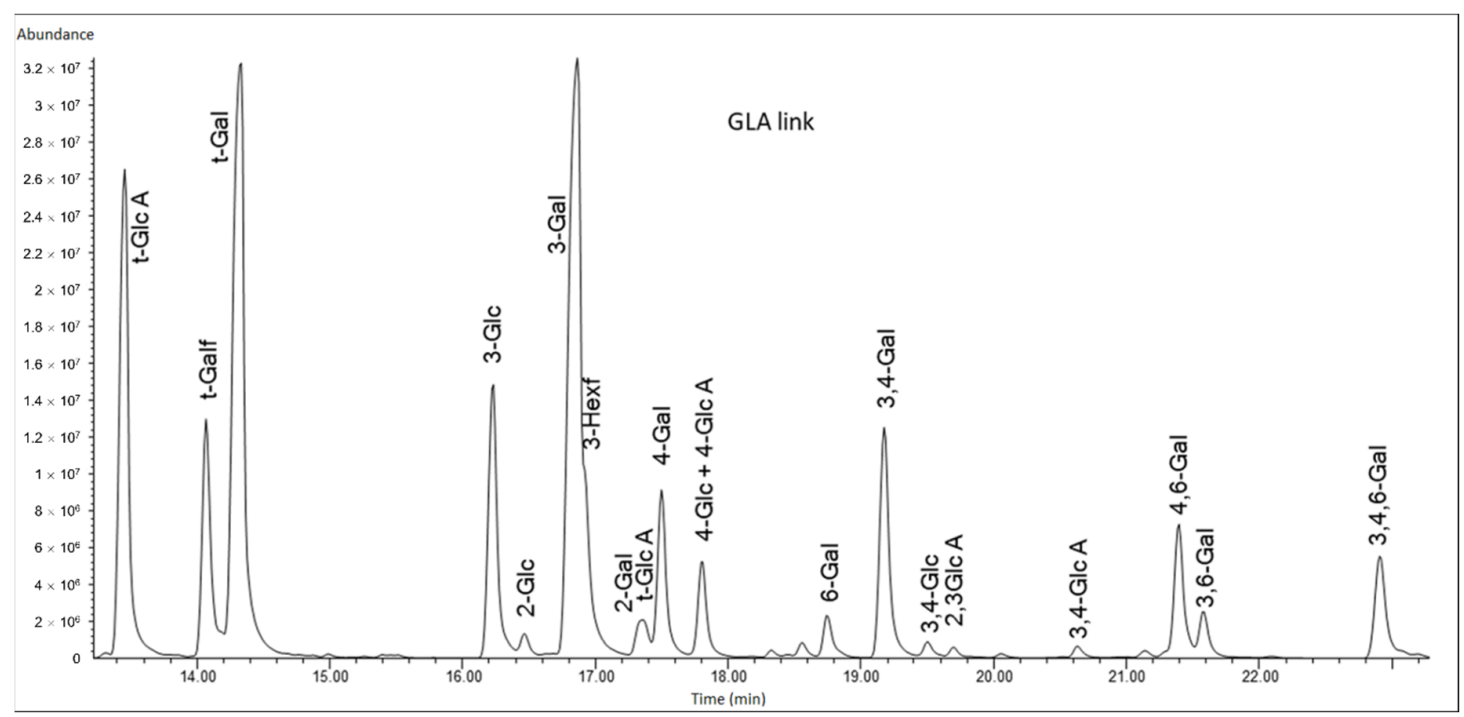

Figure 9. GC chromatogram of the PMAA derivatives of the sample. On the $\mathrm{Y}$ axes is represented the relative signal. PMAA, partially methylated alditol acetates.

Table 3. Glycosyl linkage analysis of purified high MW EPS expressed as relative percentage of each detected PMAA in the sample.

\begin{tabular}{cc}
\hline PMAA & Mole \% \\
\hline Terminal Glucuronic Acid residue (t-GlcA) & 14.2 \\
Terminal Galactofuranosyl residue (t-Galf) & 6.2 \\
Terminal Galactopyranosyl residue (t-Gal) & 21.8 \\
3 linked Glucopyranosyl residue (3-Glc) & 7.5 \\
2 linked Glucopyranosyl residue (2-Glc) & 0.5 \\
3 linked Galactopyranosyl residue (3-Gal) & 21.7 \\
3 linked Hexofuranosyl residue (3-Hexf) & 3.1 \\
2 linked Galactopyranosyl residue (2-Gal) & 0.8 \\
4 linked Galactopyranosyl residue (4-Gal) & 4.3 \\
4 linked Glucopyranosyl residue (4-Glc) & 2.0 \\
4 linked Glucuronic Acid residue (4-GlcA) & 0.5 \\
6 linked Galactopyranosyl residue (6-Gal) & 1.1 \\
3,4 linked Galactopyranosyl residue (3,4-Gal) & 6.9 \\
3,4 linked Glucopyranosyl residue (3,4-Glc) & 0.4 \\
2,3 linked Glucuronic Acid residue (2,3-GlcA) & 0.3 \\
3,4 linked Glucuronic Acid residue (3,4-GlcA) & 0.3 \\
4,6 linked Galactopyranosyl residue (4,6-Gal) & 3.8 \\
3,6 linked Galactopyranosyl residue (3,6-Gal) & 1.1 \\
3,4,6 linked Galactopyranosyl residue (3,4,6-Gal) & 3.6 \\
\hline
\end{tabular}




\subsection{Rheology Analysis}

Rheological properties of the extracted L.s. EPS were explored to assess its potential for use within a cosmetics or personal care product formulation.

Non-stressed L.s. culture, even at high cell density, showed a normal water-like behaviour. A few days after the culture entered stationary phase with continued acetic acid feeding, the cultures displayed higher viscosity. The viscosity of the stressed cell cultures and the extracted raw EPS were measured as explained in the materials and methods section using water (Newtonian fluid) and HA solution (non-Newtonian fluid) as standards. Extracted, non-purified EPS shows a viscosity higher than water with a non-Newtonian trend at higher shear rate, similar although lower compared to the pure HA solution. Stressed algae cell cultures, at low shear rates, showed a higher viscosity compared to HA solution but it showed a different trend with the increase of the shear rate, probably due to the presence of the cells inside the EPS capsule (Figure 10).

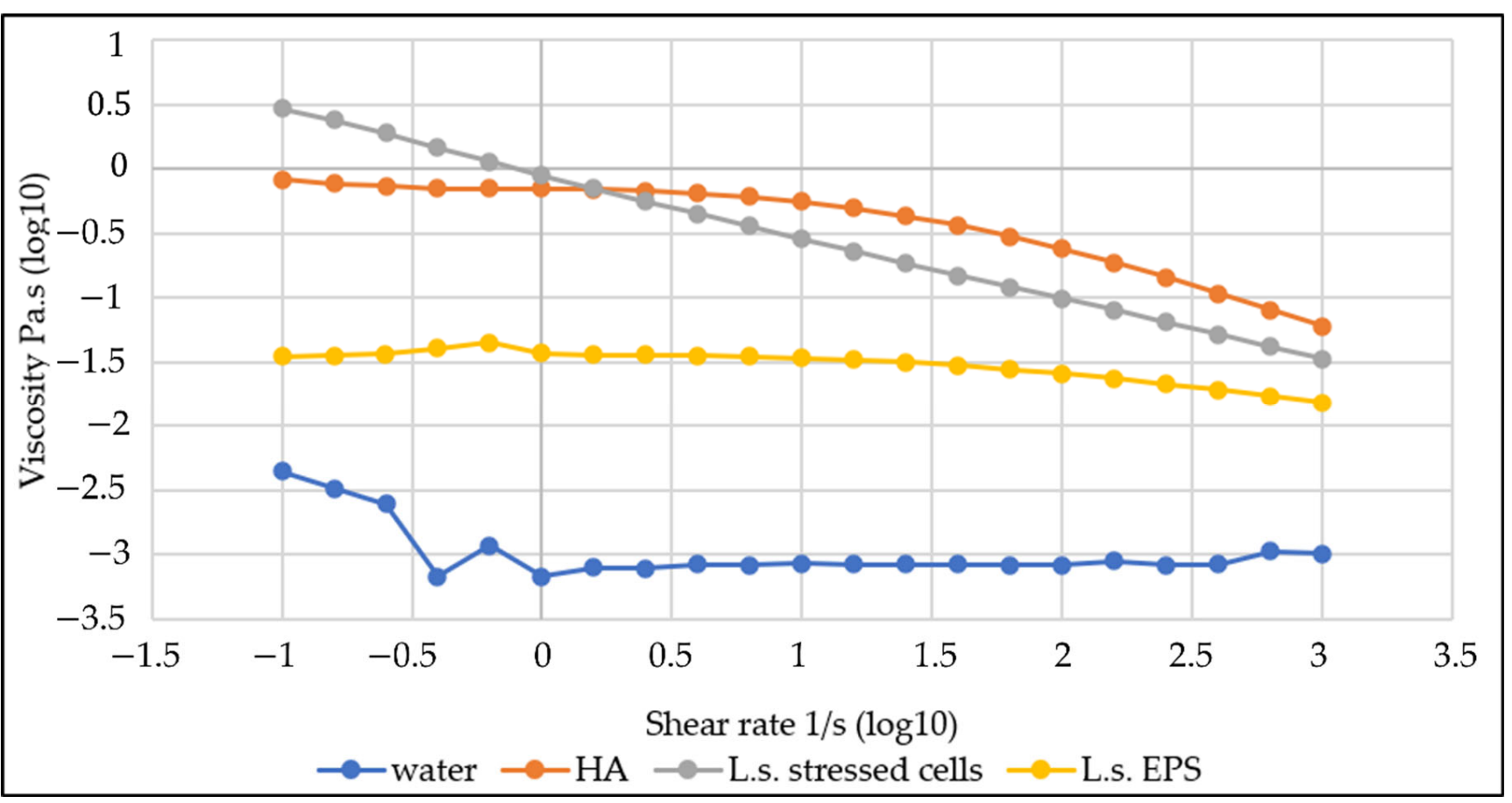

Figure 10. Viscosity measurement under variable shear stress of L.s. EPS solutions.

The high viscosity of the stressed cells suggests that, if a way to extract higher MW EPS could be found, the viscosity of pure, higher MW L.s. EPS could be equivalent or even higher than that of the HA solution.

The effect of the addition of higher salt concentrations, $2 \mathrm{M} \mathrm{NaCl}$, on the viscosity was investigated in order to further understand the behaviour of the L.s. EPS under different conditions and to potentially optimize and improve the extraction protocol. In addition to salt, other compounds that could be tested for their ability to reversibly lower the relative viscosity of the solution are SDS and urea.

With $\mathrm{NaCl}$ addition, the viscosity of the stressed cells decreased considerably (Figure 11), showing a change that could impact positively upon the extraction costs, lowering the energy required for liquid pumping and mixing expenses.

In contrast, the effect on the EPS solution was milder at a high shear rate, which could be interpreted as the mixing during extraction, suggesting that optimisation and further investigation are needed to clarify the effects. 


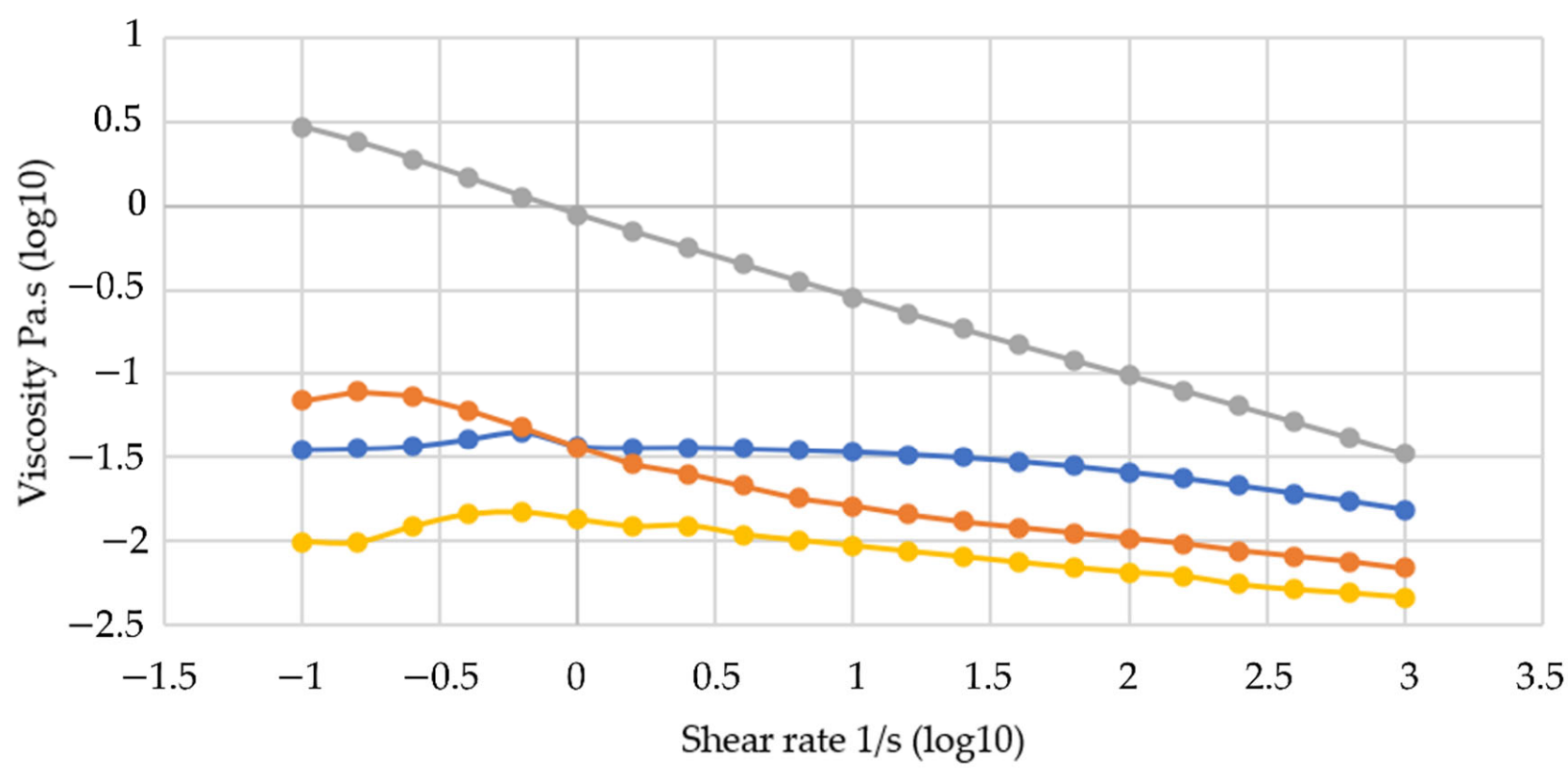

L.s. EPS $\multimap-$ L.s. EPS $2 \mathrm{M} \mathrm{NaCl} \longrightarrow$ L.s. stressed cells $\longrightarrow$ L.s. stressed cells $2 \mathrm{M} \mathrm{NaCl}$

Figure 11. Viscosity measurement under variable shear stress of L.s. EPS solutions with added $2 \mathrm{M} \mathrm{NaCl}$.

\subsection{Antioxidant Capacity and Reducing Power Quantification Assays}

Total antioxidant capacity and reducing power of purified high MW EPS were measured with in vitro assays.

As shown in Table 4, a purified high MW EPS sample showed 100 times less antioxidant capacity compared to pure vitamin C. Other values are reported in the same table for reference.

Table 4. Antioxidant capacity values extracted from literature for comparison with the value measured for L.s. EPS [21,28,29].

\begin{tabular}{cc}
\hline Extract & $\begin{array}{c}\text { Antioxidant Capacity } \\
\text { (mg EAscA/g of Dry Sample) }\end{array}$ \\
\hline orange & 50 \\
spinach & 0.6 \\
red onion & 0.84 \\
tomato & 8.6 \\
Chlamydomonas sp. & 5.7 \\
HA & 190 \\
L.s. EPS & $10.0 \pm 0.5$ \\
\hline
\end{tabular}

Another way to measure the antioxidant activity of a compound is the reducing power. Table 5 shows the measured value for purified high MW EPS and a value from literature as reference.

Table 5. Reducing power values extracted from literature [21] for comparison with the value measured for L.s. EPS in this study.

Extract

Chlamydomonas $s p$.

L.s. EPS
Reducing Power

(mg EAscA/g of Dry Sample)

$0.750 \pm 0.038$ 


\section{Discussion}

In this study, Lobochlamys segnis was investigated for the production of EPS. Culture and stress conditions were evaluated, different extraction and purification protocols were determined, and EPS was characterised, including assessment of commercially relevant properties.

The best growth and stress conditions were determined to be mixotrophic growth using acetate as the carbon source and carbon-feeding-rate controlled by $\mathrm{pH}$ value as this approach increased the $\mathrm{C} / \mathrm{N}$ ratio, thereby inducing the nitrogen-limitation-based stress on the cells. In a large-scale setting, an improved heterotrophic protocol in fermenters could be more effective in optimizing L.s. growth and stress conditions.

The extraction and purification methods utilised are relatively complicated and expensive with regard to materials and energy required, and could limit exploitation to high-value applications.

While heat extraction was identified as the best option for small scale extraction, translation to a larger scale may require super-heated water extraction, which is relatively energy expensive. Since SDS, $\mathrm{NaCl}$, and urea can be used to partially separate EPS from the cells, an optimised extraction carried out in conjunction with heat could be explored to lower the extraction temperature, decreasing time and costs.

Tangential flow filtration and size exclusion chromatography proved suitable as purification techniques, which bodes well for the development of a large-scale industrial process.

A process to cheaply and reversibly lower the viscosity of the solution would positively influence the costs involved with this step and have a substantial impact in the overall cost of production.

Growth and stress conditions of the microalgae culture were determined. In order to improve production, extraction, and purification, multifactorial experiments should be performed so that the key factors for each step can be identified and optimized. Preliminary results of L.s. EPS and L.s. stressed cells showed interesting rheological properties, and further investigations are needed, including characterisation of biocompatibility, toxicity, elasticity, plasticity, and lubrication properties in order to expand its possible application.

There is interest in the cosmetic industry for low cost, naturally-sourced thickening agents that are clear, colourless, and of neutral fragrance [30]. The extracted L.s. EPS sample appears to satisfy these criteria and shows potential as a future ingredient.

Antioxidants are often used as preservatives in food and cosmetics and as active ingredients in cosmetics because of their skin protection properties [31-33], with ascorbic acid (vitamin C) being the most powerful, most widely used, and least toxic natural antioxidant [34]. Other natural compounds with high antioxidant activity are tocopherols, carotenoids, and flavonoids [34]. The antioxidant activity of this compound is significant and could help in cosmetic formulations, lowering the costs of other antioxidant agents that need to be added.

Although the capsular PS produced by L.s. was initially suggested to be HA, our work here has shown this assumption to be incorrect. While the colour of the stained product as visualised in agarose gel electrophoresis is similar to HA, when gel migration is used, the EPS products are clearly distinguishable. Indeed, the maximum MW of the purified L.s. EPS measured (over $100 \mathrm{MDa}$ ) is vastly different from that observed for HA, $10 \mathrm{MDa}$ in Heterocephalus glaber [35]. Glycosyl composition analysis confirmed this definitively by determining the presence of galactose and glucuronic acid with traces of glucose rather than the alternating repeats of $\beta-1,4-\mathrm{D}$-glucuronic acid and $\beta-1,3-\mathrm{N}$-acetyl-D-glucosamine units characteristic of HA.

The thickening property of the high MW L.s. EPS is an interesting phenomenon, along with the antioxidant property and so far, L.s EPS characteristics can be considered as amenable to its use as a HA alternative. Both of these properties need to be more thoroughly analysed with additional characterisation for new applications being fundamental in order to fully understand and exploit the compound, together with the investigation of biocompatibility and non-toxicity of the extract. Some examples of other bioactivities that 
could be investigated in future are antiviral, bacteriostatic, antibiotic, mammalian cell growth stimulation, wound healing, and acting as a stabilizing agent, suspending agent, flocculating agent, encapsulating agent, emulsifying agent, and/or lubricating agent and volumizing activity.

Author Contributions: Conceptualization, G.S.d.V., A.S. and M.J.A.; formal analysis, G.S.d.V.; investigation, G.S.d.V.; resources, G.S.d.V.; writing-original draft preparation, G.S.d.V.; writingreview and editing, G.S.d.V., A.S. and M.J.A.; supervision, A.S. and M.J.A.; project administration, G.S.d.V.; funding acquisition, A.S. All authors have read and agreed to the published version of the manuscript.

Funding: This research received no external funding.

Institutional Review Board Statement: Not applicable.

Informed Consent Statement: Not applicable.

Data Availability Statement: The data presented in this study are available within the article.

Acknowledgments: The authors acknowledge Stavroula Balabani, Fluid Mechanics at University College London for the access to her laboratory and equipment and Anastasia Papadopoulou, Department of Mechanical Engineering at UCL, for the support during the sample analysis. The author also acknowledges Creative Proteomics, 45-1 Ramsey Road, Shirley, NY 11967, USA, for the EPS analysis with regard to molecular weight determination, composition and glycosidic linkage determination.

Conflicts of Interest: At the time of the study, G.S.d.V. and A.S. were employed by Algenuity Limited, UK, that is also sponsoring the PhD studies of G.S.d.V.

\section{References}

1. Saran, S.; Babu, V.; Chaubey, A. A Handbook on High Value Fermentation Products, Volume 2: Human Welfare; John Wiley \& Sons: Hoboken, NJ, USA, 2019; ISBN 978-1-119-55550-6.

2. De Jesus Raposo, M.; de Morais, A.; de Morais, R. Marine Polysaccharides from Algae with Potential Biomedical Applications. Mar. Drugs 2015, 13, 2967-3028. [CrossRef] [PubMed]

3. Weissmann, B.; Meyer, K. The Structure of Hyaluronic Acid and of Hyaluronic Acid from Umbilical Cord. J. Am. Chem. Soc. 1954, 76, 1753-1757. [CrossRef]

4. Lapčík, L.; Lapčík, L.; De Smedt, S.; Demeester, J.; Chabreček, P. Hyaluronan: Preparation, Structure, Properties, and Applications. Chem. Rev. 1998, 98, 2663-2684. [CrossRef]

5. Pröschold, T.; Marin, B.; Schlösser, U.G.; Melkonian, M. Molecular Phylogeny and Taxonomic Revision of Chlamydomonas (Chlorophyta). I. Emendation of Chlamydomonas ehrenberg and Chloromonas gobi, and Description of Oogamochlamys gen. nov. and Lobochlamys gen. nov. Protist 2001, 152, 265-300. [CrossRef]

6. Lang, I.; Hodac, L.; Friedl, T.; Feussner, I. Fatty Acid Profiles and Their Distribution Patterns in Microalgae: A Comprehensive Analysis of More than 2000 Strains from the SAG Culture Collection. BMC Plant Biol. 2011, 11, 124. [CrossRef] [PubMed]

7. Badour, S.S. Novel Hyaluronic Acid Produced from Algae. CA2249103A1, 27 April 1999.

8. Gopalakrishnan, K. Isolation, Characterisation and Screening of New Zealand Alpine Algae for the Production of Secondary Metabolites in Photobioreactors. Ph.D. Thesis, Department of Chemical and Process Engineering, University of Canterbury, Christchurch, New Zealand, 2015; p. 287.

9. Hyaluronic Acid Market Size Worth \$16.6 Billion By 2027. Available online: https://www.grandviewresearch.com/press-release/ global-hyaluronic-acid-market (accessed on 21 April 2020).

10. Culture Collection of Algae (SAG). Available online: https://www.uni-goettingen.de/en/culture + collection + of + algae+ $\% 28 \mathrm{sag} \%$ 29/184982.html (accessed on 16 September 2020).

11. Gorman, D.S.; Levine, R.P. Cytochrome $\mathrm{f}$ and Plastocyanin: Their Sequence in the Photosynthetic Electron Transport Chain of Chlamydomonas reinhardtii. Proc. Natl. Acad. Sci. USA 1965, 54, 1665-1669. [CrossRef]

12. Sueoka, N. Mitotic Replication of Deoxyribonucleic Acid in Chlamydomonas reinhardtii. Proc. Natl. Acad. Sci. USA 1960, 46, 83-91. [CrossRef]

13. The Algem photobioreactor, Algenuity Ltd., Eden Laboratory, Broadmead Road, Stewartby, Bedfordshire, MK43 9ND, UK. Available online: https:/ / www.algenuity.com/algem (accessed on 16 September 2020).

14. Santander, J.; Martin, T.; Loh, A.; Pohlenz, C.; Gatlin, D.M.; Curtiss, R. Mechanisms of Intrinsic Resistance to Antimicrobial Peptides of Edwardsiella ictaluri and Its Influence on Fish Gut Inflammation and Virulence. Microbiology 2013, 159, 1471-1486. [CrossRef] 
15. Merkle, R.K.; Poppe, I. Carbohydrate composition analysis of glycoconjugates by gas-liquid chromatography/mass spectrometry. In Methods in Enzymology; Guide to Techniques in Glycobiology; Academic Press: Cambridge, MA, USA, 1994; Volume 230, pp. $1-15$.

16. Willis, L.M.; Stupak, J.; Richards, M.R.; Lowary, T.L.; Li, J.; Whitfield, C. Conserved Glycolipid Termini in Capsular Polysaccharides Synthesized by ATP-Binding Cassette Transporter-Dependent Pathways in Gram-Negative Pathogens. Proc. Natl. Acad. Sci. USA 2013, 110, 7868-7873. [CrossRef]

17. Anumula, K.R.; Taylor, P.B. A Comprehensive Procedure for Preparation of Partially Methylated Alditol Acetates from Glycoprotein Carbohydrates. Anal. Biochem. 1992, 203, 101-108. [CrossRef]

18. Prieto, P.; Pineda, M.; Aguilar, M. Spectrophotometric Quantitation of Antioxidant Capacity through the Formation of a Phosphomolybdenum Complex: Specific Application to the Determination of Vitamin E. Anal. Biochem. 1999, 269, 337-341. [CrossRef]

19. Oyaizu, M. Studies on Products of Browning Reaction. Jpn. J. Nutr. Diet. 1986, 44, 307-315. [CrossRef]

20. Allard, B.; Tazi, A. Influence of Growth Status on Composition of Extracellular Polysaccharides from Two Chlamydomonas Species. Phytochemistry 1992, 32, 41-47. [CrossRef]

21. Bafana, A. Characterization and Optimization of Production of Exopolysaccharide from Chlamydomonas reinhardtii. Carbohydr. Polym. 2013, 95, 746-752. [CrossRef] [PubMed]

22. De Angelis, P.L.; Jing, W.; Graves, M.V.; Burbank, D.E.; Van Etten, J.L. Hyaluronan Synthase of Chlorella Virus PBCV-1. Science 1997, 278, 1800-1803. [CrossRef]

23. Gérin, S.; Mathy, G.; Franck, F. Modeling the Dependence of Respiration and Photosynthesis upon Light, Acetate, Carbon Dioxide, Nitrate and Ammonium in Chlamydomonas reinhardtii Using Design of Experiments and Multiple Regression. BMC Syst. Biol. 2014, 8, 96. [CrossRef]

24. Smith, R.T.; Bangert, K.; Wilkinson, S.J.; Gilmour, D.J. Synergistic Carbon Metabolism in a Fast Growing Mixotrophic Freshwater Microalgal Species Micractinium inermum. Biomass Bioenergy 2015, 82, 73-86. [CrossRef]

25. Kroen, W.K.; Rayburn, W.R. Influence of Growth Status and Nutrients on Extracellular Polysaccharide Synthesis by the Soil Alga Chlamydomonas mexicana (Chlorophyceae). J. Phycol. 1984, 20, 253-257. [CrossRef]

26. Xu, S.; Xu, X.; Zhang, L. Branching Structure and Chain Conformation of Water-Soluble Glucan Extracted from Auricularia auricula-judae. J. Agric. Food Chem. 2012, 60, 3498-3506. [CrossRef]

27. Wu, D.-T.; Meng, L.-Z.; Wang, L.-Y.; Lv, G.-P.; Cheong, K.-L.; Hu, D.-J.; Guan, J.; Zhao, J.; Li, S.-P. Chain Conformation and Immunomodulatory Activity of a Hyperbranched Polysaccharide from Cordyceps sinensis. Carbohydr. Polym. 2014, 110, 405-414. [CrossRef]

28. Pellegrini, N.; Colombi, B.; Salvatore, S.; Brenna, O.V.; Galaverna, G.; Del Rio, D.; Bianchi, M.; Bennett, R.N.; Brighenti, F. Evaluation of Antioxidant Capacity of Some Fruit and Vegetable Foods: Efficiency of Extraction of a Sequence of Solvents. J. Sci. Food Agric. 2007, 87, 103-111. [CrossRef]

29. Sadhasivam, G.; Muthuvel, A.; Pachaiyappan, A.; Thangavel, B. Isolation and Characterization of Hyaluronic Acid from the Liver of Marine Stingray Aetobatus narinari. Int. J. Biol. Macromol. 2013, 54, 84-89. [CrossRef]

30. Unilever, Sustainable Living. Available online: https:/ / www.unilever.co.uk/sustainable-living/ (accessed on 13 November 2020).

31. Vinardell, M.P.; Ugartondo, V.; Mitjans, M. Potential Applications of Antioxidant Lignins from Different Sources. Ind. Crops Prod. 2008, 27, 220-223. [CrossRef]

32. Morganti, P.; Bruno, C.; Guarneri, F.; Cardillo, A.; Del Ciotto, P.; Valenzano, F. Role of Topical and Nutritional Supplement to Modify the Oxidative Stress. Int. J. Cosmet. Sci. 2002, 24, 331-339. [CrossRef] [PubMed]

33. Rodrigues, F.; Palmeira-de-Oliveira, A.; das Neves, J.; Sarmento, B.; Amaral, M.H.; Oliveira, M.B. Medicago spp. Extracts as Promising Ingredients for Skin Care Products. Ind. Crops Prod. 2013, 49, 634-644. [CrossRef]

34. Gülçin, İ. Antioxidant Activity of Food Constituents: An Overview. Arch. Toxicol. 2012, 86, 345-391. [CrossRef]

35. Fisher, G.J. Cancer Resistance, High Molecular Weight Hyaluronic Acid, and Longevity. J. Cell Commun. Signal. 2015, 9, 91-92. [CrossRef] 